Article

\title{
Optimization Method for Multiple Measures to Mitigate Line Overloads in Power Systems
}

\author{
Jinghan $\mathrm{He}^{1}$, Ninghui Han ${ }^{1}$ and Ziqi Wang ${ }^{2, *}$ \\ 1 Power System Protection and Control Research Laboratory, Beijing Jiaotong University, Beijing 100044, China; \\ jhhe@bjtu.edu.cn (J.H.); 20117017@bjtu.edu.cn (N.H.) \\ 2 Automation Control Design Center, State Grid Economic and Technological Research Institute, \\ Beijing 102209, China \\ * Correspondence: wangziqi@chinasperi.com; Tel.: +86-152-0134-3340
}

Citation: He, J.; Han, N.; Wang, Z. Optimization Method for Multiple Measures to Mitigate Line Overloads in Power Systems. Energies 2021, 14, 6201. https://doi.org/10.3390/ en14196201

Academic Editor: Ahmed Abu-Siada

Received: 15 July 2021

Accepted: 6 September 2021

Published: 28 September 2021

Publisher's Note: MDPI stays neutral with regard to jurisdictional claims in published maps and institutional affiliations.

Copyright: (c) 2021 by the authors. Licensee MDPI, Basel, Switzerland. This article is an open access article distributed under the terms and conditions of the Creative Commons Attribution (CC BY) license (https:// creativecommons.org/licenses/by/ $4.0 /)$.

\begin{abstract}
Line overload is one of the important causal factors of cascading failures and blackouts in power systems. An optimization method for protection and control measures to mitigate line overloads is proposed in this study. The method consists of two main parts, i.e., the modeling process and the solving process. In the modeling process, an optimization model including overload protection and emergency control measures is developed using PFT (Power Flow Tracing). In the solving process, a multi-stage optimization method using IBSO (Improved Brain Storm Optimization algorithm) is proposed to obtain the final result. The aim of this study is to form a coordinated protection and control strategy that reduces the power on the overloaded line within the safety limits and minimizes the load loss of the power system. The simulation results show the effectiveness of the proposed method.
\end{abstract}

Keywords: line overload; overload protection; load shedding; emergency control; DC emergency control; power flow transfer

\section{Introduction}

The widespread interconnection of power systems and the increased demand for electricity have promoted large-scale transmission of power, driving grids close to their operational limits. Line overloads play an important role in the development of cascading failures and blackouts in power systems [1-3]. In the case of line overloads, rapid line removal and improper coordination of protection and control measures will result in the massive power flow transferring, expanding the scope of grid accidents $[4,5]$. On the contrary, effective and appropriate protection and control measures can alleviate line overloads, mitigate the consequences of cascading events, and avoid blackouts. This is of great significance to ensure the safe operation of power systems [6]. Currently, the measures for line overload mainly include overload protection, traditional emergency control, and DC (Direct Current) emergency control. Experts and scholars have conducted a series of studies on the above measures to ensure the safe and stable operation of power systems [7].

Research on overload protection is mainly focused on the adjustment of operating time. Reference [8] proposed a thermal prediction method using online measurements of voltage and current, as well as line material parameters and weather data. Based on the thermal stability limits of transmission lines, references $[9,10]$ delayed the operating time of overload protection, providing more time for the effective implementation of control measures. The time adjustment can change the operation sequence of the protection and control devices, but it does not essentially enable the coordination and optimization of protection and control measures.

Traditional emergency control measures include generator control and load shedding. Control strategies are usually obtained through optimization or sensitivity methods [11]. 
In reference [12], a DC model was used to obtain the critical loads and generators, and the corresponding control measures were calculated based on the sensitivity of nodes. A multi-level control architecture was proposed in reference [13], which can solve control problems at different time scales. When the optimization methods are adopted, the control measures are usually simplified and represented by continuous constraints. In reference [14], a data-driven preventive control optimization strategy was introduced, which deployed differential evolution to obtain preventive control measures for transient stabilization of the power system. Reference [15] provided an overview of intelligent optimization algorithms that can be used for continuous load shedding in power systems and discussed the advantages and limitations of different algorithms. As an intelligent optimization algorithm, BSO can also be used for the continuous optimization of traditional control measures [16]. However, the controlling values of traditional emergency control measures may be discrete, continuous, or hybrid in practical engineering, which has not been thoroughly analyzed in the existing studies.

The implementation of emergency control for DC transmission lines depends on the development of HVDC (High-Voltage Direct Current) transmission technology. HVDC, with its fast response time of control schemes and short time overload capability, can be used as a new control object to share heavy loads and alleviate overloads due to power flow transferring $[17,18]$. Reference [19] redefined the grid security defense system and analyzed the control functions of DC systems. In reference [20], the advantages of DC emergency control were presented regarding ensuring the safety and stability of power systems at the sending and receiving ends. However, DC emergency control measures are relatively independent at present. Due to their fast response time, they are usually implemented prior to traditional control measures. There is still a lack of synergistic optimization in DC emergency control measures and traditional emergency control measures.

In this study, a new optimization method for multiple measures is proposed to alleviate line overloads. Compared with previous studies on overload protections, not only the operating time but also the behavior (trip or not) of the overload protection is optimized. Compared with previous studies on control strategies, the discrete and continuous constraints of different control measures are fully considered. Furthermore, the method integrates all types of feasible protection and control measures into a unified optimization model with PFT and obtains the optimal protection and control strategy with the proposed IBSO in multiple stages. The method can effectively reduce the amount of load loss compared with other studies.

The rest of the paper is structured as follows: Section 2 introduces the performance of different types of measures. Section 3 describes the mathematical approaches used in this study. Section 4 illustrates the detailed process of the optimization method, which includes a process overview, modeling process based on PFT, and solving process based on IBSO. The test cases with AC (Alternating Current)/DC hybrid systems are provided in Section 5. Conclusions are presented in Section 6.

\section{Analysis of Protection and Control Measures}

Overload protections, traditional emergency controls, and DC emergency controls are all effective measures to alleviate line overloads. Overload protection can isolate an overloaded transmission line by tripping a circuit breaker, which can rapidly reduce the power of the overloaded line to 0 . Control measures can alter the output, absorbed or transmitted power of generators, loads, and DC lines, thereby changing the distribution of power flow and reducing the power of overloaded lines.

\subsection{Controlling Values of Different Measures}

Controlling value of overload protection: A protection device can be used to isolate and restore an overloaded line by operating the circuit breaker. The $0-1$ variables can be used directly to indicate the operations of protection devices. When the overload protection 
operates, the transmission line is isolated, and the power on the transmission line will rapidly drop to 0 . Otherwise, the line will maintain its transmission status.

Controlling value of traditional control measure: Traditional control measures include generator control and load shedding. Generally, generator control includes continuous adjustment of output power, shut-down, and start-up of generating units [21]. The power adjustment amount of generators and loads can be continuous or discrete values. In this study, there is no restriction on the type of values.

Controlling value of DC emergency control measure: The control system of a DC line consists of three levels: the main control level, the pole control level, and the valve control unit [22]. DC emergency control is an additional control function at the main control level. During the control process, the command from the dispatching center is combined with an additional modulation signal, and the result is sent to the pole control level. This result will be further processed and the processed control commands, such as the control command of the trigger angle, will be sent to the valve control unit, as shown in Figure $1[23,24]$. As a result, the power on the DC transmission line can be continuously adjusted.

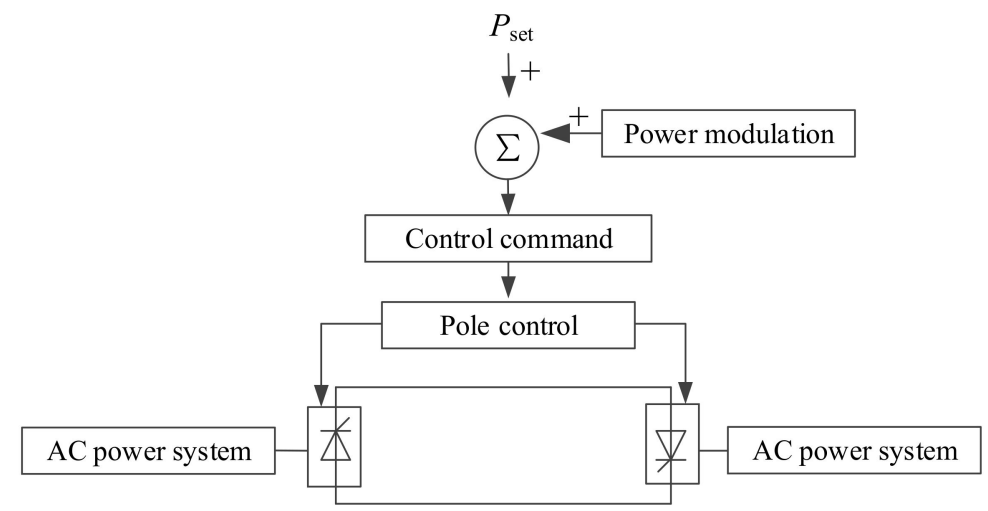

Figure 1. Control mode of DC transmission lines.

\subsection{Response Times of Different Measures}

Operating time of overload protection: Overload protection can trip a transmission line immediately after a time delay. The investigation results of the blackout $[25,26]$ in the United States and Canada on 14 August 2003 show that three $345 \mathrm{kV}$ transmission lines of FE company in northern Ohio tripped one after another due to load increasing, overheating, sagging and contacting with tree branches, lasting up to $52 \mathrm{~min}$. For a single transmission line, the time from the start of the overload to the end of line removal was more than $10 \mathrm{~min}$. Reference [27] analyzed the thermal stability of transmission lines. The limit time was from 8 to $10 \mathrm{~min}$ in the test case. Consistent with existing research [28,29], the temperature of a line, rather than the current, is used to measure the degree of overload in this study, and the operating time of overload protection can be obtained based on the thermal limits of transmission lines.

Response time of traditional control measure: The response time (the time of the complete control process from failure occurrence to measure execution) of load shedding or generator tripping is short, which can ensure the cooperation between these measures and overload protections [27]. The response time of power improvements varies widely. Reference [30] classifies different types of reserves according to their response speeds, as shown in Table 1. 
Table 1. Response time of the reserve.

\begin{tabular}{ccc}
\hline Reserve & Response Time & State \\
\hline instantaneous reserve & seconds & sync with power system \\
fast spinning reserve & $0-10 \mathrm{~min}$ & sync with power system \\
fast non-spinning reserve & $0-10 \mathrm{~min}$ & out-sync \\
thirty-minute reserve & $10-30 \mathrm{~min}$ & out-sync \\
sixty-minute reserve & $30-60 \mathrm{~min}$ & out-sync \\
cold reserve & $>60 \mathrm{~min}$ & out-sync \\
\hline
\end{tabular}

As can be seen from Table 1, the time scales of some reserves can be within a few minutes. With improvements in communication systems and the widespread use of power electronic devices in generator auxiliaries, the responsiveness of traditional control measures will be further improved.

Response time of DC emergency control measure: The response speed of DC emergency control is fast, and the power on a DC transmission line can reach the preset value quickly. Typically, the response time can be hundreds of milliseconds [31]. In practical engineering, the response speed of DC emergency control is influenced not only by the control system of the DC transmission line but also by the response speed of the power systems at sending and receiving ends.

\section{Mathematical Algorithms}

\subsection{PFT}

PFT is a mathematical algorithm for obtaining the paths of power transmission from generators to loads in a power system. Due to its advantages of simplicity and clarity, it is widely used in the calculation of electrovalence, network loss allocation, and stability control of power systems.

Based on the proportional sharing principle, PFT decomposes the power on the transmission line and finds its suppliers and consumers [32,33]. As shown in Figure $2, P_{g 1}$ and $P_{g 2}$ are injected power. $P_{l 3}, P_{l 4}$ are output power. The power from $P_{g 1}$ to $P_{l 3}$ is:

$$
P_{g 1-l 3}=\frac{P_{g 1}}{P_{g}} P_{l 3}=\frac{P_{l 3}}{P_{l}} P_{g 1}
$$

where $P_{g}$ is the sum of the injected power; $P_{1}$ is the sum of the output power; $P_{g}=P_{l}=P_{g 1}$ $+P_{g 2}=P_{l 3}+P_{l 4}$.

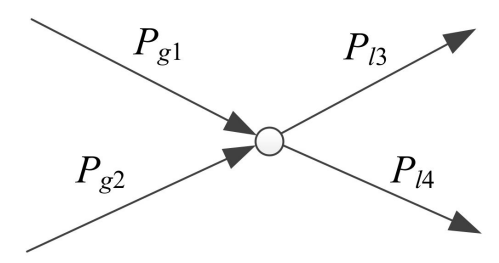

Figure 2. Power flow at a node.

The system in Figure 3 is taken as an example. There are two loads, $x 1$ and x2, two generators, $\mathrm{y} 1$ and $\mathrm{y} 2$, and four transmission lines, $\mathrm{z} 1, \mathrm{z} 2, \mathrm{z} 3$, and $\mathrm{z} 4$. Power distribution is carried out along the direction of power flow starting from $\mathrm{y} 1$ and $\mathrm{y} 2$ to $\mathrm{x} 1$ and $\mathrm{x} 2$. According to Equation (1), the active power from $\mathrm{y} 1$ to $\mathrm{z} 2$ is $3 \mathrm{MW}$, and that from $\mathrm{z} 2$ to $\mathrm{x} 2$ is $1.875 \mathrm{MW}$. The transmission path can be described as y1-z2-x2 with $1.875 \mathrm{MW}$ active power transmitted. 


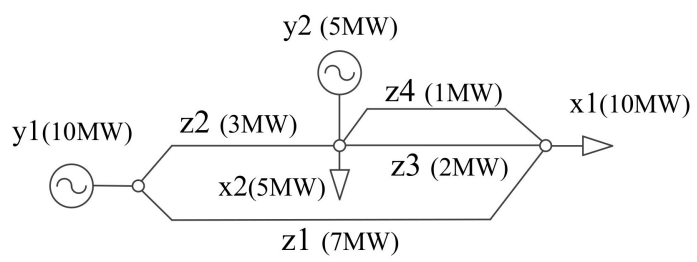

Figure 3. Three-bus system.

The transmission paths obtained by PFT are shown in Table 2.

Table 2. Transmission paths in three-bus system.

\begin{tabular}{ccc}
\hline Path & Devices & Active Power \\
\hline 1 & y1-z1-x1 & $7 \mathrm{MW}$ \\
2 & $\mathrm{y} 1-\mathrm{z} 2-\mathrm{z} 3-\mathrm{x} 1$ & $0.75 \mathrm{MW}$ \\
3 & $\mathrm{y} 1-\mathrm{z} 2-\mathrm{z} 4-\mathrm{x} 1$ & $0.375 \mathrm{MW}$ \\
4 & $\mathrm{y} 1-\mathrm{z} 2-\mathrm{x} 2$ & $1.875 \mathrm{MW}$ \\
5 & $\mathrm{y} 2-\mathrm{z} 3-\mathrm{x} 1$ & $1.25 \mathrm{MW}$ \\
6 & $\mathrm{y} 2-\mathrm{z} 4-\mathrm{x} 1$ & $0.625 \mathrm{MW}$ \\
7 & $\mathrm{y} 2-\mathrm{x} 2$ & $3.125 \mathrm{MW}$ \\
\hline
\end{tabular}

Generally, a large amount of active power is transmitted in the grid, and the reactive power is compensated locally in the power flow transmission. Consistent with reference [34-36], this study focuses on active power flow tracing, and the tracing results are used to build an optimization model.

\subsection{BSO and IBSO}

\subsubsection{Introduction of BSO}

BSO is a swarm intelligence algorithm that can simulate the brainstorming process of group members. It is effective for solving optimization problems in power systems [37]. The process is shown in Figure 4a.

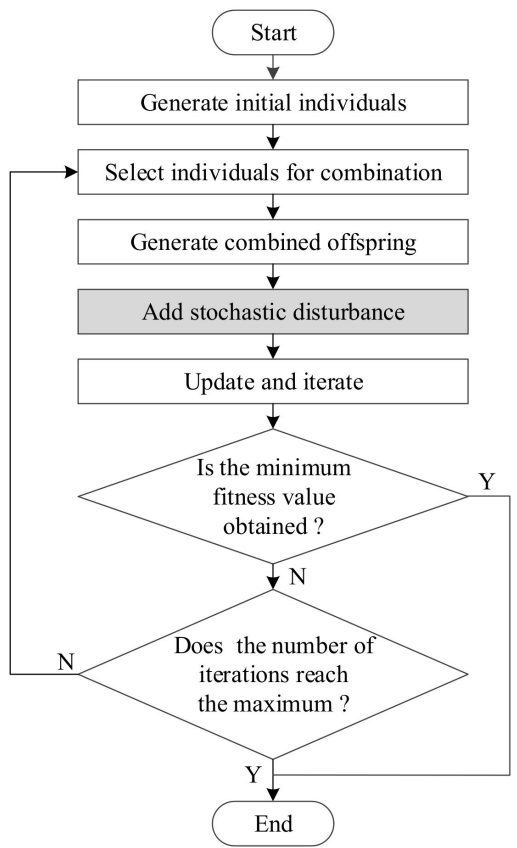

(a)

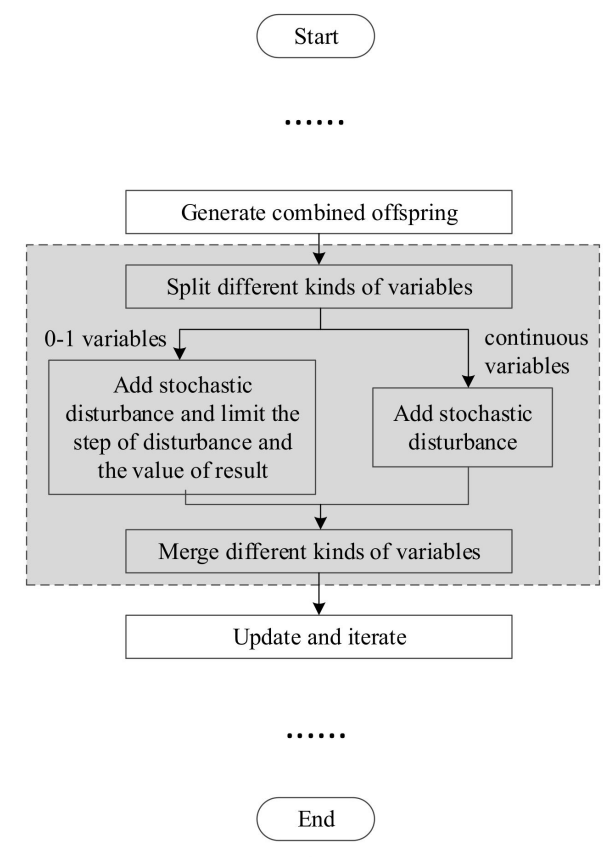

(b)

Figure 4. (a) Flow chart of BSO; (b) IBSO with variable splitting and disturbance splitting. 
First, $d$ initial individuals are randomly generated in the feasible space. The individuals can be denoted as:

$$
J_{i}=\left[j_{1}, j_{2}, j_{3}, j_{4}, j_{5}, j_{6} \ldots\right] i=1,2,3 \ldots d
$$

Each individual represents a potential result. Two individuals are randomly selected for the combination, as is:

$$
J_{\text {sel }}=\left[j_{\text {sel } 1}, j_{\text {sel } 2}, j_{\text {sel } 3}, j_{\text {sel } 4}, j_{\text {sel } 5}, j_{\text {sel } 6} \ldots\right]=D_{1} J_{1}+D_{2} J_{2}
$$

where $J_{1}$ and $J_{2}$ are the selected individuals; $D_{1}$ and $D_{2}$, denoted as $\left[d_{11}, d_{12}, d_{13} \ldots\right]$ and $\left[d_{21}\right.$, $\left.d_{22}, d_{23} \ldots\right]$ are random vectors of equal dimensionality to $J . d$ is generated randomly from 0 to $1 . d_{1 j}+d_{2 j}=1 ; J_{\text {sel }}$ is the combined offspring. $J_{1}$ and $J_{2}$ can be selected by clustering methods.

Stochastic disturbance is placed on $J_{\text {sel }}$ to produce a new individual. The new individual $J_{\text {new }}$ is:

$$
\begin{aligned}
& J_{\text {new }}= {\left[j_{\text {new } 1}, j_{\text {new } 2}, j_{\text {new } 3} \ldots j_{\text {newe }}, \ldots\right] } \\
& j_{\text {newe }}=j_{\text {sele }}+\xi \times n(\mu, \sigma)
\end{aligned}
$$

where $\xi$ is the step length; $n(\mu, \sigma)$ is the Gaussian random function. The new individual meeting the constraints will be retained. The criteria for updating is:

$$
F\left(J_{\text {new }}\right)<F(J)
$$

where $J$ is the worse one of $J_{1}$ and $J_{2}$ with a larger target value; $F($ ) is the objective function. In the updating process, the fitness of the retained individual is better than that of the replaced one. The above processes are repeated until the minimum target value is obtained or the number of iterations reaches the maximum.

\subsubsection{Introduction of IBSO}

The IBSO proposed in this study improves the stochastic disturbance of BSO. Different from traditional optimization problems, there are $0-1$ variables (representing the operations of protection devices) and continuous variables to be optimized. Therefore, variable splitting and disturbance splitting is added into the calculation process. The improvement is shown in Figure $4 b$.

For individual $J_{i}$ :

$$
J_{i}=\left[j_{1}, j_{2}, j_{3} \ldots j_{l}, j_{l+1}, j_{l+2} \ldots\right]
$$

where $j_{e}(1 \leq e \leq l)$ is a $0-1$ variable; $j_{e}(e \geq l+1)$ is a continuous variable. Each individual represents a potential result. Two individuals are randomly selected for combination according to Equation (3).

Since there are $0-1$ variables and continuous variables in a single individual, the variables are split, and different disturbances are added. The new individual $J_{\text {new }}$ is:

$$
J_{\text {new }}=\left[j_{\text {new } 1}, j_{\text {new } 2}, j_{\text {new } 3} \ldots j_{\text {newe }}, \ldots . . .\right.
$$

Considering the value range of $j_{\text {newe }}(1 \leq e \leq l), j_{\text {newe }}$ can be calculated as:

$$
\begin{aligned}
& j_{\text {newe }}=f i x\left[j_{\text {sele }}+\xi_{1} \times n(\mu, \sigma)\right] \\
& \left|\xi_{1}\right|<1
\end{aligned}
$$

where $\mathrm{fix}[]$ is to take a relatively close value between 0 and $1 ; n(\mu, \sigma)$ is the Gaussian random function; $\xi_{1}$ is the step length to adjust the range of disturbance on $0-1$ variables.

$j_{\text {newe }}(e \geq l+1)$ can be calculated as:

$$
j_{\text {newe }}=j_{\text {sele }}+\xi_{2} \times n(\mu, \sigma)
$$


where $\xi_{2}$ is the step length to adjust the range of disturbance on continuous variables. With the splitting process, $0-1$ variables and continuous variables are disturbed separately. Different kinds of variables are combined together to form $J_{\text {new }}$. The criteria for updating are the same as those in Equation (5).

\section{Optimization Method for Multiple Measures}

From the perspective of effects, overload protection and control measures can change the power flow distribution in power systems. Overload protections and DC emergency control measures can change the transmitted power on AC or DC lines, while traditional control measures can change the output or absorbed power of different generators or loads. From the perspective of response time, the time scale of different measures varies from seconds to hours. Therefore, protection and control measures can be optimized together.

\subsection{Process Overview}

The implementation of the optimization method depends on the information of basic structure and parameters of a power system, the information of available protection and control measures (including overload protections, and controllable power adjustment amount of generators, loads, and DC transmission lines), and real-time measuring data (including power, current, and temperature) of transmission lines. The optimization process is started if any transmission line is overloaded. Through the calculation of limit time, selection of protection and control devices, modeling process, and solving process, the final protection and control strategy is formed. The power of overloaded lines can be reduced within safe limits by the protection and control strategy. The flow chart of the optimization method in this study is shown in Figure 5.

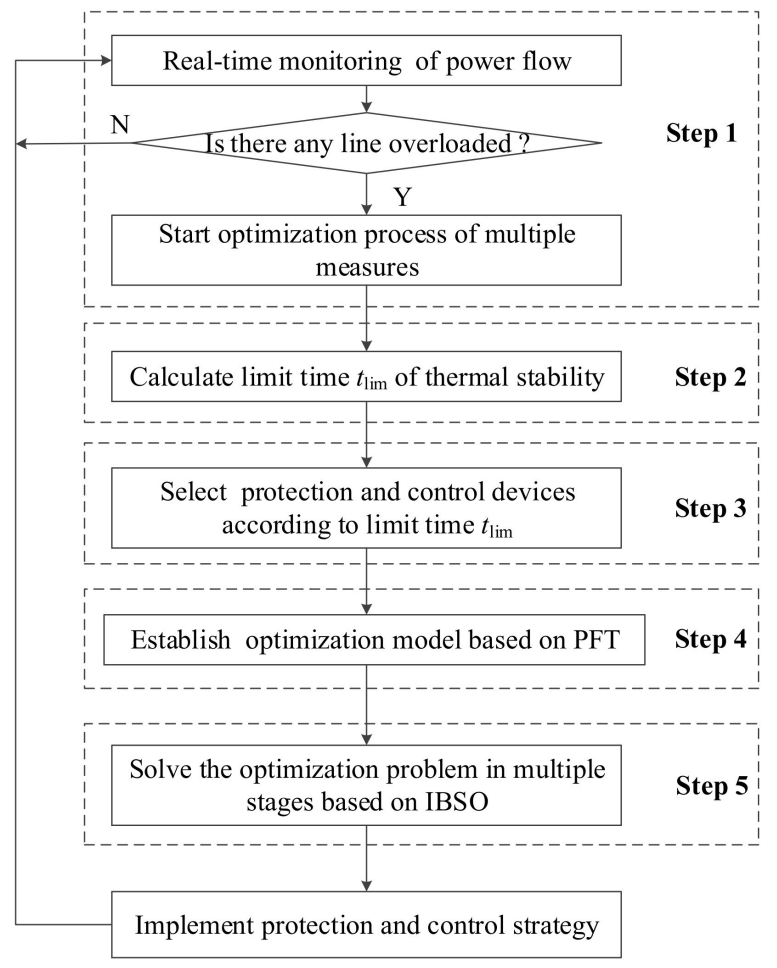

Figure 5. Flow chart of the optimization method.

The detailed steps are as follows:

Step 1-Power monitoring: monitor the power flow of transmission lines in real time and start the optimization process if any transmission line is overloaded.

Step 2-Caculation of limit time: calculate the limit time $t_{\text {lim }}$ of thermal stability for the overloaded line [38]: 


$$
t_{\lim }=\frac{m C_{p}}{I^{2} \beta-0.57 \pi \lambda_{f} R_{\mathrm{e}}^{0.485}-\pi D \varepsilon \sigma_{B}} \ln \frac{\left(I^{2} \beta-0.57 \pi \lambda_{f} R_{\mathrm{e}}^{0.485}-\pi D \varepsilon \sigma_{B} H\right)\left(t_{\max }-t_{a}\right)+\left(I^{2} R+q_{s}\right)}{\left(I^{2} \beta-0.57 \pi \lambda_{f} R_{\mathrm{e}}^{0.485}-\pi D \varepsilon \sigma_{B} H\right)\left(t_{n}-t_{a}\right)+\left(I^{2} R+q_{s}\right)}
$$

where $C_{p}$ is the heat capacity of the transmission line; $I$ is the current on the transmission line; $\beta$ is the change rate of resistance with temperature; $\lambda_{f}$ is the thermal conductivity of air; $R_{\mathrm{e}}$ is the Reynolds number; $D$ is the external diameter of the transmission line; $\sigma_{B}$ is the Stefan-Boltzman constant; $H$ is the correlation function of $t_{\max }$ and $H=\left[\left(t_{\max }+273\right)^{2}-\right.$ $\left.\left(t_{a}+273\right)^{2}\right]\left(t_{\max }+t_{a}+546\right) ; t_{\max }$ is the maximum temperature of the transmission line; $t_{a}$ is the ambient temperature; $R$ is the resistance corresponding to the operating temperature; $t_{n}$ is the operating temperature of the transmission line; $q_{s}$ is the capacity of heat in unit time by solar radiation.

When multiple lines are overloaded, the shortest $t_{\text {lim }}$ can be selected as the limit time.

Step 3-Selection of protection and control measures: adjust the operating time of the overload protections for overloaded lines to $t_{\mathrm{lim}}$, and select the corresponding overload protections, generators, loads, and DC lines with response time less than $t_{\lim }$ for coordination and optimization.

Step 4-Modeling process: find transmission paths with PFT and establish an optimization model including $0-1$ and continuous variables. The detailed process is shown in Section 4.2.

Step 5-Solving process: prioritize different measures, and calculate optimal result with IBSO in multiple stages. The detailed process is shown in Section 4.3.

\subsection{Modeling Process Based on PFT}

With PFT shown in Section 3.1, all transmission paths in the power system can be obtained. The power adjustment amount of a single path is taken as a basic variable of the optimization model, and the power adjustment amount of path $i$ is defined as $\triangle P^{i}$. To minimize the load loss, the objective function is:

$$
\min . F\left(\Delta P^{\mu}\right)=\sum_{x \in X}\left(\left|L_{x}\right|-\left|L_{x}+\sum_{m \in M} \Delta P_{x}^{m}\right|\right), \mu \in \psi
$$

where $F()$ is the objective function representing total load loss in a power system; $\triangle P^{\mu}$ is the power adjustment amount of path $\mu ; \psi$ is the set of all paths in the system; $L_{x}$ is the initial absorbed power of load $x ; \triangle P_{x}{ }^{m}$ is the adjustment amount of the absorbed power of load $x$ in path $m ; M$ is the set of paths connecting load node $x ; X$ is the set of loads in the power system.

Power adjustment should be carried out on the premise of satisfying the power constraints of generators, loads, and transmission lines. The power constraint of generators is:

$$
\sum_{n \in N} \Delta P_{y}^{n} \in G_{y}^{\text {fsb }} y \in Y
$$

where $\triangle P_{y}{ }^{n}$ is the adjustment amount of the output power of generator $y$ in path $n$; $N$ is the set of paths connecting generator node $y ; G_{y}$ fsb is the set of controllable power adjustment amount of generator $y$ within $t_{\text {lim }}$, which can be positive or negative, and can be discrete values, continuous values, or mixed values; $Y$ is the set of generators in the power system.

The power constraint of loads is:

$$
\sum_{m \in M} \Delta P_{x}^{m} \in L_{x}^{\mathrm{fsb}} x \in X
$$

where $L_{x}{ }^{\mathrm{fsb}}$ is the set of controllable power adjustment amount of load $x$ within $t_{\text {lim }}$, which can be discrete, continuous, or mixed values. The definitions of other variables are the same as those in Equation (2). 
The power constraint of DC transmission lines is:

$$
T_{z}^{\min } \leq T_{z}+\sum_{r \in R} \Delta P_{z}^{r} \leq f_{z} T_{z}^{\text {set }} z \in Z_{\mathrm{dc}}
$$

where $T_{z}$ is the initial power transmitted on line $z ; \triangle P_{z}{ }^{r}$ is the adjustment amount of the transmitted power on line $z$ in path $r ; R$ is the set of paths through line $z ; T_{z}$ min and $T_{z}$ set are the minimum limit and rated capacity of active power on line $z ; f_{z}$ is the coefficient of transmission power considering overload capability. $Z_{\mathrm{dc}}$ is the set of DC transmission lines in the power system.

The power constraint of AC transmission lines is:

$$
T_{k}^{\min } \leq T_{k}+\sum_{w \in W} \Delta P_{k}^{w} \leq T_{k}^{\max } k \in Z_{\text {ac-nonver }}
$$

where $T_{k}$ is the initial power transmitted on line $k ; \triangle P_{k}^{w}$ is the adjustment amount of transmitted power on line $k$ in path $w ; W$ is the set of paths through line $k ; T_{k}{ }^{\min }$ and $T_{k}{ }^{\max }$ are the minimum and maximum limits of active power on line $k ; Z_{\text {ac-nonver }}$ is the set of $A C$ transmission lines transmitting power within their capacities in the system.

For overloaded lines, the protection variable $c$ is introduced in Equation (15), which is:

$$
\left(1-c_{k}\right) T_{k}^{\min } \leq T_{k}+\sum_{w \in W} \Delta P_{k}^{w} \leq\left(1-c_{k}\right) T_{k}^{\max } k \in Z_{\text {ac-over }}
$$

where $c_{k}$ is the protection variable of line $k, c_{k}=0$ or 1 . When $c_{k}=0$, the overload protection for line $k$ does not operate. When $c_{k}=1$, the protection operates to trip line $k$. $Z_{\text {ac-over }}$ is the set of overloaded AC transmission lines.

For the paths connected with the same generator and load through parallel lines, their power adjustments are interrelated. If the control measures are implemented separately, the power on some transmission lines with small capacities may exceed the power limits because of the power adjustment of transmission lines with large capacities. Therefore, it is necessary to restrict the power adjustment amount of these parallel paths. The power constraint of parallel paths [39] is:

$$
\frac{\Delta P^{a}}{g_{a}}=\frac{\Delta P^{b}}{g_{b}} a, b \in B_{o}, o=1,2,3 \ldots
$$

where $B_{0}, o=1,2,3 \ldots$ are different sets of parallel paths. Considering the power control of DC lines, the parallel paths with the same DC lines and parallel paths without DC lines are classified separately. $a$ and $b$ are paths in a same set; $g_{a}$ and $g_{b}$ are the split ratios of path $a$ and $b$.

From the foregoing, the optimization model for alleviating line overload is:

$$
\begin{aligned}
& \min . F\left(\Delta P^{\mu}\right)=\sum_{x \in X}\left(\left|L_{x}\right|-\left|L_{x}+\sum_{m \in M} \Delta P_{x}{ }^{m}\right|\right), \mu \in \psi \\
& \left\{\begin{array}{l}
\sum_{m \in M} \Delta P_{x}{ }^{m} \in L_{x}{ }^{\mathrm{fsb}} x \in X \\
\sum_{n \in N} \Delta P_{y}{ }^{n} \in G_{y}{ }^{\mathrm{fsb}} y \in Y \\
T_{z}{ }^{\min } \leq T_{z}+\sum_{r \in R} \Delta P_{z}^{r} \leq f_{z} T_{z}{ }^{\text {set }} z \in Z_{\mathrm{dc}} \\
T_{k}{ }^{\min } \leq T_{k}+\sum_{w \in W} \Delta P_{k}^{w} \leq T_{k}{ }^{\text {max }} k \in Z_{\text {ac-nonver }} \\
\left(1-c_{k}\right) T_{k}{ }^{\min ^{w}} \leq T_{k}+\sum_{w \in W} \Delta P_{k}^{w} \leq\left(1-c_{k}\right) T_{k}{ }^{\text {max }} k \in Z_{\text {ac-over }} \\
\Delta P^{a} / g_{a}=\Delta P^{b} / g_{b} a, b \in B_{o}, o=1,2,3 \ldots
\end{array}\right.
\end{aligned}
$$




\subsection{Solving Process Based on IBSO}

Considering the performance of protection and control measures, different measures are prioritized, and the optimization problem can be solved in multiple stages.

Stage I: Optimization of overload protections. Considering technical and economic advantages, the overload protections are optimized first. The adjustment amounts of output (absorbed/transmitted) power of generators (loads/DC lines) are set to 0 . Only the power constraints of $\mathrm{AC}$ lines and parallel paths are retained. The first three constraints in optimization model (18) can be modified as:

$$
\left\{\begin{array}{c}
\sum_{m \in M} \Delta P_{x}^{m}=0 x \in X \\
\sum_{n \in N} \Delta P_{y}{ }^{n}=0 y \in Y \\
\sum_{r \in R} \Delta P_{z}^{r}=0 z \in Z_{\mathrm{dc}}
\end{array} .\right.
$$

According to the constraints in Equation (19), the load loss (target value) is equal to 0, which is the optimal value. If the optimal solution can be obtained by the IBSO proposed in Section 3.2, the optimization result can be the output, and the protection strategy can be generated by $c_{k}, k \in Z_{\mathrm{ac}-\mathrm{over}}$ directly. The solving process is terminated, and the overload can be eliminated by protections. Otherwise, go to Stage II.

Stage II: Optimization of overload protections and DC emergency control measures. The increase of power on DC transmission lines can relieve the power transmission pressure of the related AC lines directly. Compared with traditional control measures, the benefits of DC emergency control measures include better economic performance and more rapid response. The adjustment amounts of output (absorbed) power of generators (loads) are set to 0 . The power constraints of AC lines, DC lines, and parallel paths are retained. The first two constraints in the optimization model (18) can be modified as:

$$
\left\{\begin{array}{c}
\sum_{m \in M} \Delta P_{x}{ }^{m}=0 x \in X \\
\sum_{n \in N} \Delta P_{y}{ }^{n}=0 y \in Y
\end{array} .\right.
$$

The load loss (target value) is equal to 0 according to the constraints in Equation (20). Same as Stage I, if the optimal solution can be obtained by IBSO, the optimization result will be output directly. The protection strategy can be generated by $c_{k}, k \in Z_{\mathrm{ac}-o v e r}$ and the control strategy can be obtained by Equation (21), as is:

$$
\Delta P_{z}=\sum_{r \in R} \Delta P_{z}^{r}
$$

where $\triangle P_{z}$ is the adjustment amount of transmitted power on DC line $z$.

The solving process is terminated, and the overload can be eliminated by the coordination of protections and DC emergency control measures. Otherwise, go to Stage III.

Stage III: Optimization of overload protections, DC emergency control measures, and power adjustment of generators. In order to avoid load loss, all kinds of protection and control measures except load shedding are optimized in this stage. The first constraint in optimization model (18) can be modified as:

$$
\sum_{m \in M} \Delta P_{x}{ }^{m}=0 x \in X .
$$

The load loss (target value) is equal to 0 according to Equation (22). Same as Stages I and II, if the optimal solution can be obtained, the optimization result will be output directly. The protection strategy can be generated by $c_{k}, k \in Z_{\text {ac-over }}$. The control strategy can be obtained by Equation (23): 


$$
\left\{\begin{aligned}
\Delta P_{y} & =\sum_{n \in N} \Delta P_{y}{ }^{n} \\
\Delta P_{z} & =\sum_{r \in R} \Delta P_{z}{ }^{r}
\end{aligned}\right.
$$

where $\triangle P_{y}$ is the adjustment amount of output power of generator $y$.

The solving process is terminated, and the overload can be eliminated by the coordination of protections, DC emergency control measures, and power adjustment of generators. Otherwise, go to Stage IV.

Stage IV: Optimization of all protection and control measures. The optimization result of Equation (18) can be output directly. The protection strategy can be generated by variable c. The control strategy can be obtained by Equation (24):

$$
\left\{\begin{aligned}
\Delta P_{x} & =\sum_{m \in M} \Delta P_{x}{ }^{m} \\
\Delta P_{y} & =\sum_{n \in N} \Delta P_{y}{ }^{n} \\
\Delta P_{z} & =\sum_{r \in R} \Delta P_{z}^{r}
\end{aligned}\right.
$$

where $\triangle P_{x}$ is the adjustment amount of absorbed power of load $x$. The overload can be eliminated through the coordination of protection and control measures.

\section{Test Cases}

In this section, a five-bus system and a 29-bus system are used as test systems to demonstrate the effectiveness of the optimization method. The five-bus test system is used to introduce the detailed process, and the 29-bus test system is used to illustrate the advantages of this method.

\subsection{Five-Bus Test System}

A five-bus test system [38] is shown in Figure 6. During the interruption maintenance of line $z 2, z 3$ is broken accidentally, and the power on line $\mathrm{z} 1$ exceeds the limit. The active power and transmission capacity of each line is shown in Table 3 . The transmission capacity of a DC transmission line is 1.2 times the rated value.

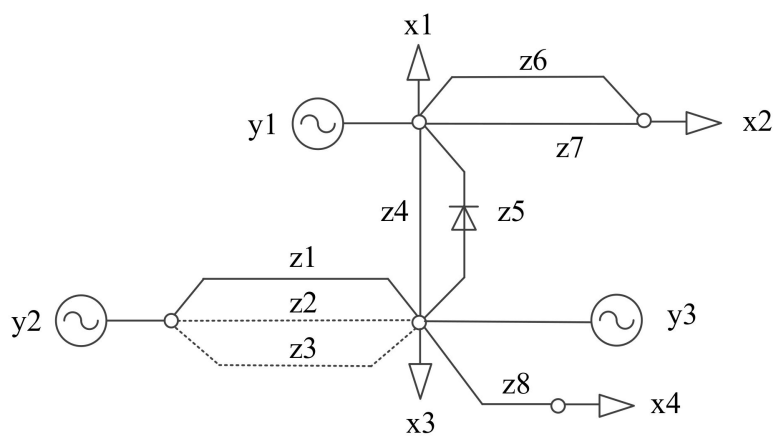

Figure 6. Five-bus test system.

Table 3. Active power and transmission capacities of lines in the five-bus system.

\begin{tabular}{cccccc}
\hline $\begin{array}{c}\text { Transmission } \\
\text { Line }\end{array}$ & $\begin{array}{c}\text { Active } \\
\text { Power (p.u.) }\end{array}$ & $\begin{array}{c}\text { Transmission } \\
\text { Capacity } \\
\text { (p.u.) }\end{array}$ & $\begin{array}{c}\text { Transmission } \\
\text { Line }\end{array}$ & $\begin{array}{c}\text { Active } \\
\text { Power (p.u.) }\end{array}$ & $\begin{array}{c}\text { Transmission } \\
\text { Capacity } \\
\text { (p.u.) }\end{array}$ \\
\hline z1 & 6.23 & 4.92 & z5 & 3.68 & 4.42 \\
z2 & - & - & z6 & 3.39 & 4.84 \\
z3 & - & - & z7 & 3.39 & 4.84 \\
z4 & 1.30 & 1.86 & z8 & 1.41 & 2.01 \\
\hline
\end{tabular}

The initial and adjustable active power of generators and loads are shown in Table 4. 
Table 4. Initial and adjustable active power of generators and loads in the five-bus system.

\begin{tabular}{|c|c|c|c|c|c|}
\hline Generator & $\begin{array}{l}\text { Initial Power } \\
\text { (p.u.) }\end{array}$ & $\begin{array}{l}\text { Power Adjustment } \\
\text { Amount (p.u.) }\end{array}$ & Load & $\begin{array}{l}\text { Initial Power } \\
\text { (p.u.) }\end{array}$ & $\begin{array}{l}\text { Power Adjustment } \\
\text { Amount (p.u.) }\end{array}$ \\
\hline y1 & 4.52 & $\begin{array}{l}-4.52 \sim 0(\leq 5 \mathrm{~min}) \\
-4.52 \sim 0(\leq 10 \mathrm{~min}) \\
-4.52 \sim 0(\leq 30 \mathrm{~min}) \\
-6.23 \sim 0,2(\leq 5 \mathrm{~min})\end{array}$ & $\mathrm{x} 1$ & 2.72 & $-2.72 \sim 0(\leq 1 \mathrm{~min})$ \\
\hline$y^{2}$ & 6.23 & $\begin{array}{l}-6.23 \sim 0,2,4(\leq 10 \mathrm{~min}) \\
-6.23 \sim 0,2,4(\leq 30 \mathrm{~min})\end{array}$ & $x 2$ & 6.78 & $-6.78,-3.39,0(\leq 1 \mathrm{~min})$ \\
\hline y3 & 3.21 & $\begin{array}{l}-3.21 \sim 0(\leq 5 \mathrm{~min}) \\
-3.21 \sim 1(\leq 10 \mathrm{~min}) \\
-3.21 \sim 1(\leq 30 \mathrm{~min})\end{array}$ & $\begin{array}{l}x 3 \\
x 4\end{array}$ & $\begin{array}{l}3.05 \\
1.41\end{array}$ & $\begin{array}{c}-3.05,-1.5,0(\leq 1 \mathrm{~min}) \\
-1.41,0(\leq 1 \mathrm{~min})\end{array}$ \\
\hline
\end{tabular}

The optimization process is started. The limit time $t_{\text {lim }}$ of overloaded line $\mathrm{z} 1$ is calculated based on Equation (10), and the longest operating time of overload protection for line $\mathrm{z} 1$ is adjusted to $t_{\lim }$, which is $12 \mathrm{~min}$. The adjustable devices in Table 4 are screened. Control measures that can be implemented within 12 min are retained. According to PFT, all paths are searched from different generators to different loads along the power flow direction. The tracing results are shown in Table 5.

Table 5. Transmission paths in the five-bus system.

\begin{tabular}{cccccc}
\hline Path & Devices & Path & Devices & Path & Devices \\
\hline 1 & y1-x1 & 8 & y2-z1-z4-z7-x2 & 15 & y3-z5-z6-x2 \\
2 & y1-z6-x2 & 9 & y2-z1-z5-z7-x2 & 16 & y3-z4-z7-x2 \\
3 & y1-z7-x2 & 10 & y2-z1-x3 & 17 & y3-z5-z7-x2 \\
4 & y2-z1-z4-x1 & 11 & y2-z1-z8-x4 & 18 & y3-x3 \\
5 & y2-z1-z5-x1 & 12 & y3-z4-x1 & 19 & y3-z8-x4 \\
6 & y2-z1-z4-z6-x2 & 13 & y3-z5-x1 & - & - \\
7 & y2-z1-z5-z6-x2 & 14 & y3-z4-z6-x2 & - & - \\
\hline
\end{tabular}

An optimization model is established as follows with $0-1$ variable $c_{1}$ and continuous variables $\triangle P^{\mu} \mu=1,2,3 \ldots 19$, which represent the running status of the overload protection and the power adjustment amounts of different paths, respectively.

$$
\begin{aligned}
& \min . F\left(\Delta P^{\mu}\right)=\left(\left|L_{1}\right|-\left|L_{1}+\Delta P^{1}+\Delta P^{4}+\Delta P^{5}+\Delta P^{12}+\Delta P^{13}\right|\right)+ \\
& \left(\left|L_{2}\right|-\left|L_{2}+\Delta P^{2}+\Delta P^{3}+\Delta P^{6}+\Delta P^{7}+\Delta P^{8}+\Delta P^{9}+\Delta P^{14}+\Delta P^{15}+\Delta P^{16}+\Delta P^{17}\right|\right) \\
& +\left(\left|L_{3}\right|-\left|L_{3}+\Delta P^{10}+\Delta P^{18}\right|\right)+\left(\left|L_{4}\right|-\left|L_{4}+\Delta P^{11}+\Delta P^{19}\right|\right), \mu=1,2,3 \ldots .19 \\
& \\
& \left\{\begin{array}{l}
\Delta P^{1}+\Delta P^{2}+\Delta P^{3} \in-4.52 \sim 0 \\
\Delta P^{4}+\Delta P^{5}+\Delta P^{6}+\Delta P^{7}+\Delta P^{8}+\Delta P^{9}+\Delta P^{10}+\Delta P^{11} \in-6.23 \sim 0,2,4 \\
\Delta P^{12}+\Delta P^{13}+\Delta P^{14}+\Delta P^{15}+\Delta P^{16}+\Delta P^{17}+\Delta P^{18}+\Delta P^{19} \in-3.21 \sim 1 \\
\Delta P^{1}+\Delta P^{4}+\Delta P^{5}+\Delta P^{12}+\Delta P^{13} \in-2.72 \sim 0 \\
\Delta P^{2}+\Delta P^{3}+\Delta P^{6}+\Delta P^{7}+\Delta P^{8}+\Delta P^{9}+\Delta P^{14}+\Delta P^{15}+\Delta P^{16}+\Delta P^{17} \in-6.78,-3.39,0 \\
\Delta P^{10}+\Delta P^{18} \in-3.05,-1.5,0 \\
\Delta P^{11}+\Delta P^{19} \in-1.41,0 \\
0 \leq 3.68+\Delta P^{5}+\Delta P^{9}+\Delta P^{13}+\Delta P^{15}+\Delta P^{17} \leq 4.42 \\
0 \leq 6.23+\Delta P^{4}+\Delta P^{5}+\Delta P^{6}+\Delta P^{7}+\Delta P^{8}+\Delta P^{9}+\Delta P^{10}+\Delta P^{11} \leq\left(1-c_{1}\right) \times 4.92 \\
0 \leq 1.30+\Delta P^{4}+\Delta P^{6}+\Delta P^{8}+\Delta P^{12}+\Delta P^{14}+\Delta P^{16} \leq 1.86 \\
0 \leq 3.39+\Delta P^{2}+\Delta P^{6}+\Delta P^{7}+\Delta P^{14}+\Delta P^{15} \leq 4.84 \\
0 \leq 3.39+\Delta P^{3}+\Delta P^{8}+\Delta P^{9}+\Delta P^{16}+\Delta P^{17} \leq 4.84 \\
0 \leq 1.41+\Delta P^{11}+\Delta P^{19} \leq 2.01 \\
\Delta P^{6} / \Delta P^{8}=\Delta P^{7} / \Delta P^{9}=\Delta P^{14} / \Delta P^{16}=\Delta P^{15} / \Delta P^{17}=1
\end{array}\right.
\end{aligned}
$$

The overload protection is optimized in Stage I. IBSO with variable splitting and disturbance splitting is used to solve the problem, but there is no feasible solution after searching. The constraints are modified, and different kinds of measures are optimized in Stages II, III, and IV in turn. In Stage IV, the initial solutions can be found, where 
$\xi_{2}=0.25$. After cross iteration and mutation, the optimal result can be obtained. The final protection and control strategy calculated by Equation (24) is: the overload protection does not operate, the output power of generator y2 is reduced by 1.31 p.u., the output power of generator $\mathrm{y} 3$ is increased by 1 p.u., and the $x 1$ sheds loads by 0.31 p.u. After the implementation of control measures, the operation status of each line is shown in Table 6, and the overload of line $\mathrm{z} 1$ is eliminated.

Table 6. Operation status of transmission lines in the five-bus system.

\begin{tabular}{cccccc}
\hline $\begin{array}{c}\text { Transmission } \\
\text { Line }\end{array}$ & $\begin{array}{c}\text { Active } \\
\text { Power (p.u.) }\end{array}$ & Overload & $\begin{array}{c}\text { Transmission } \\
\text { Line }\end{array}$ & $\begin{array}{c}\text { Active } \\
\text { Power (p.u.) }\end{array}$ & Overload \\
\hline z1 & 4.92 & No & z5 & 3.68 & No \\
z2 & - & No & z6 & 3.39 & No \\
z3 & - & No & z7 & 3.39 & No \\
z4 & 0.99 & No & z8 & 1.41 & No \\
\hline
\end{tabular}

\subsection{9-Bus Test System}

A regional power system with 29 buses in eastern China [38] is shown in Figure 7. Line $\mathrm{z} 6$ is broken accidentally, and the power on line z7 exceeds its limit. The active power and transmission capacity of each line is shown in Table 7. Lines z1, z2, z5, and z19 are DC lines with constant power control. The transmission capacity of a DC transmission line is 1.2 times the rated value.

The optimization process is started. $T_{\text {lim }}$ of overloaded line $\mathrm{z} 7$ is calculated based on Equation (10) and the longest operating time of overload protection is adjusted to $t_{\mathrm{lim}}$. The initial active power and power adjustment amount of generators and loads within $t_{\text {lim }}$ are shown in Table 8. All loads are continuously adjustable.

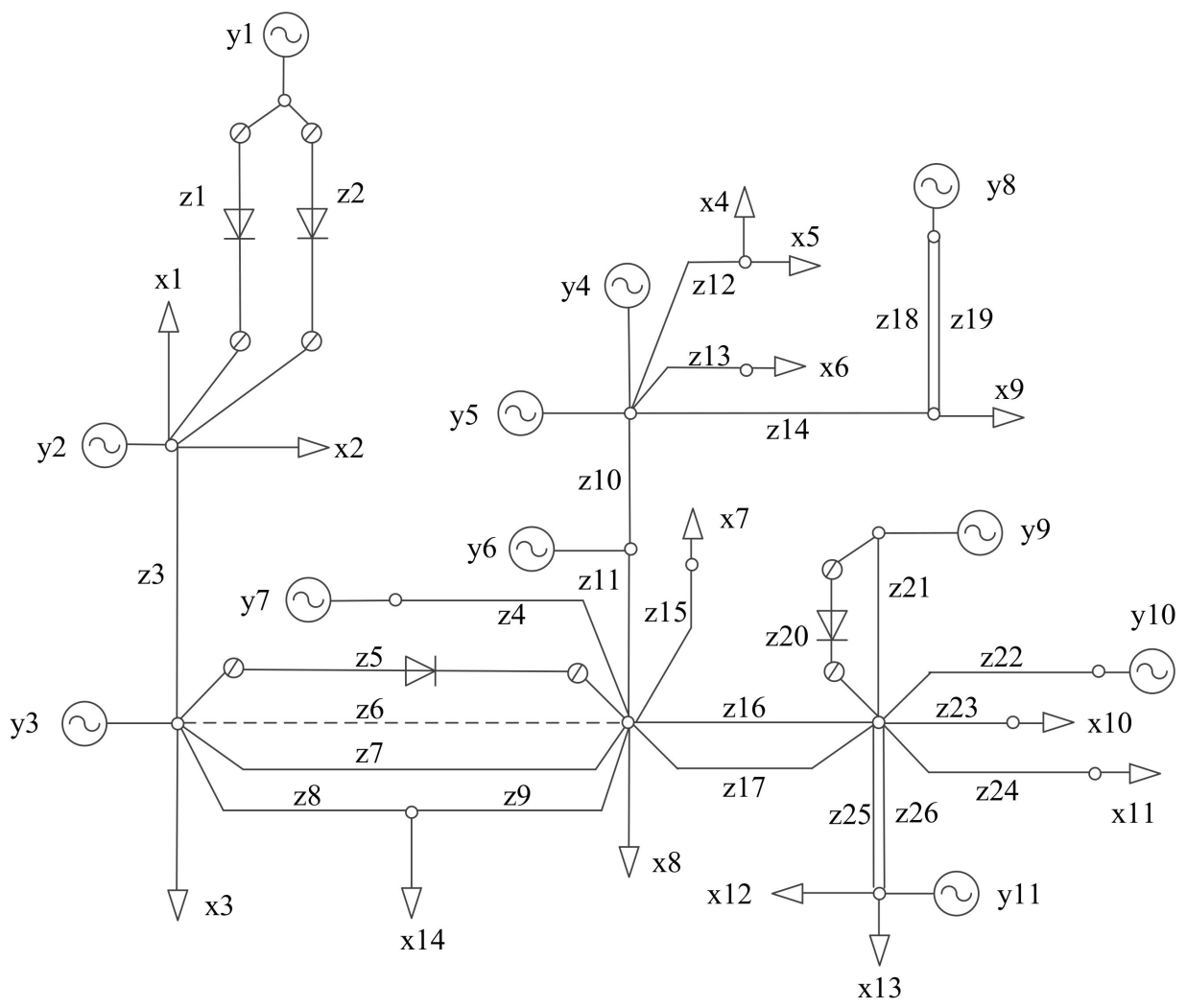

Figure 7. Regional power system in eastern China. 
Table 7. Active power and maximum power capacity of transmission lines in the regional power system.

\begin{tabular}{cccccc}
\hline $\begin{array}{c}\text { Transmission } \\
\text { Line }\end{array}$ & $\begin{array}{c}\text { Active } \\
\text { Power (p.u.) }\end{array}$ & $\begin{array}{c}\text { Transmission } \\
\text { Capacity } \\
\text { (p.u.) }\end{array}$ & $\begin{array}{c}\text { Transmission } \\
\text { Line }\end{array}$ & $\begin{array}{c}\text { Active } \\
\text { Power (p.u.) }\end{array}$ & $\begin{array}{c}\text { Transmission } \\
\text { Capacity } \\
\text { (p.u.) }\end{array}$ \\
\hline z1 & 2.00 & 2.40 & z14 & 4.20 & 5.25 \\
z2 & 2.00 & 2.40 & z15 & 1.41 & 2.01 \\
z3 & 1.30 & 1.85 & z16 & 1.41 & 2.01 \\
z4 & 4.50 & 5.63 & z17 & 0.56 & 0.80 \\
z5 & 3.00 & 3.60 & z18 & 0.56 & 0.80 \\
z6 & - & - & z19 & 1.00 & 1.20 \\
z7 & 2.80 & 2.00 & z20 & 0.55 & 0.79 \\
z8 & 2.80 & 5.00 & z21 & 2.30 & 3.29 \\
z9 & 2.00 & 2.86 & z22 & 2.20 & 3.14 \\
z10 & 1.31 & 1.87 & z23 & 1.51 & 2.16 \\
z11 & 3.50 & 5.00 & z24 & 1.48 & 2.11 \\
z12 & 2.60 & 3.71 & z25 & 1.48 & 2.11 \\
z13 & 4.62 & 5.78 & - & - & - \\
\hline
\end{tabular}

Table 8. Initial and adjustable active power of generators and loads in the regional power system.

\begin{tabular}{cccccc}
\hline Generator & $\begin{array}{c}\text { Initial } \\
\text { Power (p.u.) }\end{array}$ & $\begin{array}{c}\text { Power Adjustment } \\
\text { Amount (p.u.) }\end{array}$ & Load & $\begin{array}{c}\text { Initial } \\
\text { Power (p.u.) }\end{array}$ & $\begin{array}{c}\text { Maximum Rate for } \\
\text { Load Shedding }\end{array}$ \\
\hline y1 & 4.00 & $-4,0$ & $x 1$ & 4.00 & $100 \%$ \\
y2 & 4.80 & $-4.8,-2.4,0$ & $x 2$ & 6.10 & $100 \%$ \\
y3 & 10.20 & $-10.2 \sim 0.8$ & $x 3$ & 0.80 & $100 \%$ \\
y4 & 4.00 & $-4 \sim 0$ & $x 4$ & 2.50 & $100 \%$ \\
y5 & 4.72 & $-4.72,0$ & $x 5$ & 1.00 & $100 \%$ \\
y6 & 0.69 & $0.69,0$ & $x 6$ & 2.60 & $100 \%$ \\
y7 & 4.50 & $-4.50 \sim 0$ & $x 7$ & 4.20 & $100 \%$ \\
y8 & 1.12 & $-1.12 \sim 0,0.1,0.2$ & $x 8$ & 5.58 & $100 \%$ \\
y9 & 1.55 & $-1.55 \sim 0,0.1,0.2,0.3$ & $x 9$ & 5.74 & $100 \%$ \\
y10 & 2.30 & $-2.3 \sim 0$ & $x 10$ & 2.20 & $100 \%$ \\
y11 & 2.30 & $-2.3 \sim 0,0.5$ & $x 11$ & 1.51 & $100 \%$ \\
- & - & - & $x 12$ & 2.26 & $100 \%$ \\
- & - & - & $x 13$ & 3.00 & $100 \%$ \\
\hline
\end{tabular}

The final protection and control strategy is that the overload protection for line $\mathrm{z} 7$ operates, the power on DC line $\mathrm{z} 5$ is increased by 0.6 p.u. The amount of load loss is 0 . After the implementation of the strategy, the operation status of each line is shown in Table 9, and the overload of line $\mathrm{z} 7$ is eliminated.

Table 9. Operation status of transmission lines in the regional power system.

\begin{tabular}{cccccc}
\hline $\begin{array}{c}\text { Transmission } \\
\text { Line }\end{array}$ & $\begin{array}{c}\text { Active } \\
\text { Power (p.u.) }\end{array}$ & Overload & $\begin{array}{c}\text { Transmission } \\
\text { Line }\end{array}$ & $\begin{array}{c}\text { Active } \\
\text { Power (p.u.) }\end{array}$ & Overload \\
\hline z1 & 2.00 & No & z14 & 4.20 & No \\
z2 & 2.00 & No & z15 & 1.41 & No \\
z3 & 1.30 & No & z16 & 1.41 & No \\
z4 & 4.50 & No & z17 & 0.56 & No \\
z5 & 3.60 & No & z18 & 0.56 & No \\
z6 & - & No & z19 & 1.00 & No \\
z7 & - & No & z20 & 0.55 & No \\
z8 & 5.00 & No & z21 & 2.30 & No \\
z9 & 2.00 & No & z22 & 2.20 & No \\
z10 & 1.31 & No & z23 & 1.51 & No \\
z11 & 3.50 & No & z24 & 1.48 & No \\
z12 & 2.60 & No & z25 & 1.48 & - \\
z13 & 4.62 & No & - & - & \\
\hline
\end{tabular}




\subsection{Comparison and Analysis}

\subsubsection{Comparison of IBSO and BSO}

$\mathrm{BSO}$ is used to solve the optimization problem in Section 5.2. When the combined offspring of $\mathrm{C} 7$ equals 1 , the values of $\mathrm{C} 7$ in new individuals with stochastic disturbance are shown in Figure 8.

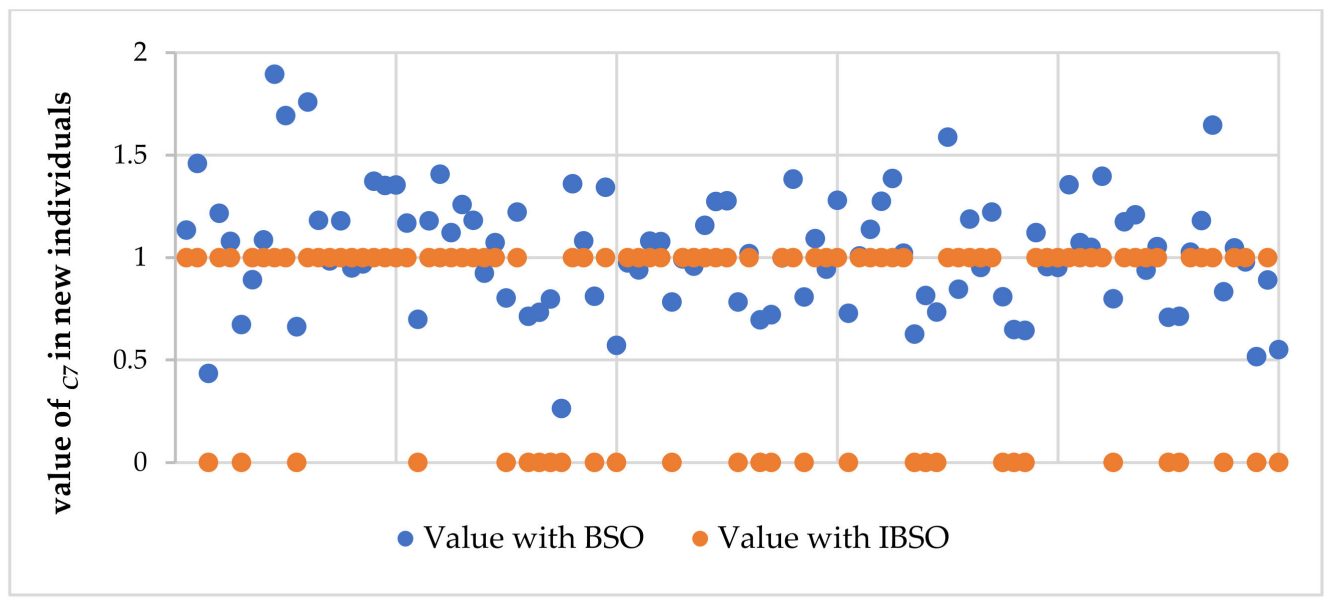

Figure 8. The values of C7 in new individuals with BSO and IBSO.

The feasible individual is hard to be found by BSO, since different dimensional spaces cannot be searched for simultaneously. Continuous disturbances are added, which cannot meet the requirements of the $0-1$ variables.

Compared with BSO, IBSO provides more possibility of obtaining feasible individuals by adjusting step lengths and setting the value ranges of different variables, respectively. Therefore, the optimal result is easier to be found by IBSO, and the generation of infeasible new individuals can be effectively avoided.

\subsubsection{Comparison of Solving Process in Multiple Stages and in One Stage}

Without the prioritization of protection and control measures, the above problems are optimized and analyzed. For the test system in Figure 7, multiple protection and control strategies can be obtained, as shown in Table 10.

It can be seen from Table 10 that the protection and control strategy with the multistage optimization method, which is the same as the 13th strategy without the multi-stage optimization method, can eliminate overload only with a protection device and a DC transmission line, avoiding the adjustment process of generators. Compared with other strategies, the 13th strategy uses the least devices with a minimum power adjustment amount of generators, as shown in Figure 9. Without prioritizing protection and control measures, a large number of solutions will be generated. In extreme cases, the best solution is difficult to be identified, and the optimal strategy may be missed. 
Table 10. Protection and control strategies for alleviating overloads.

\begin{tabular}{|c|c|}
\hline No. & Strategy \\
\hline 1 & c7 $=1$, y3 $\downarrow 0.6$ p.u. ${ }^{1}, y 8 \uparrow 0.1$ p.u. ${ }^{2}, y 11 \uparrow 0.5$ p.u. \\
\hline 2 & c7 $=1$, y $3 \downarrow 0.6$ p.u., y9 $\uparrow .1$ p.u., y $11 \uparrow 0.5$ p.u. \\
\hline 3 & $\mathrm{c} 7=1, \mathrm{z} 5 \uparrow 0.1$ p.u., $\mathrm{y} 3 \downarrow 0.5$ p.u., $\mathrm{y} 11 \uparrow 0.5$ p.u. \\
\hline 4 & c7 $=1, \mathrm{z} 5 \uparrow 0.2$ p.u., y $3 \downarrow 0.4$ p.u., y $8 \uparrow 0.2$ p.u., y $9 \uparrow 0.2$ p.u. \\
\hline 5 & $\mathrm{c} 7=1, \mathrm{z} 5 \uparrow 0.3$ p.u., $\mathrm{y} 3 \downarrow 0.3$ p.u., $\mathrm{y} 9 \uparrow 0.3$ p.u. \\
\hline 6 & $\mathrm{c} 7=1, \mathrm{z} 5 \uparrow 0.3$ p.u., $\mathrm{y} 3 \downarrow 0.3$ p.u., $\mathrm{y} 8 \uparrow 0.1$ p.u., $\mathrm{y} 9 \uparrow 0.2$ p.u. \\
\hline 7 & $\mathrm{c} 7=1, \mathrm{z} 5 \uparrow 0.3$ p.u., $\mathrm{y} 3 \downarrow 0.3$ p.u., $\mathrm{y} 8 \uparrow 0.2$ p.u., $\mathrm{y} 9 \uparrow 0.1$ p.u. \\
\hline 8 & $\mathrm{c} 7=1, \mathrm{z} 5 \uparrow 0.4$ p.u., y3 $\downarrow 0.2$ p.u., $\mathrm{y} 8 \uparrow 0.2$ p.u. \\
\hline 9 & $\mathrm{c} 7=1, \mathrm{z} 5 \uparrow 0.4$ p.u., $\mathrm{y} 3 \downarrow 0.2$ p.u., $\mathrm{y} 9 \uparrow 0.2$ p.u. \\
\hline 10 & 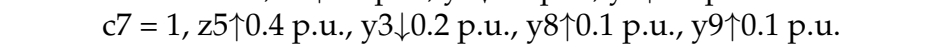 \\
\hline 11 & $\mathrm{c} 7=1, \mathrm{z} 5 \uparrow 0.5$ p.u., y3 $\downarrow 0.1$ p.u., y $8 \uparrow 0.1$ p.u. \\
\hline 12 & 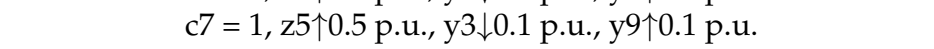 \\
\hline 13 & c7 $=1, \mathrm{z} 5 \uparrow 0.6$ p.u. \\
\hline 14 & $\mathrm{c} 7=0, \mathrm{z} 5 \uparrow 0.6$ p.u., $\mathrm{y} 3 \downarrow 0.2$ p.u., $\mathrm{y} 8 \uparrow 0.2$ p.u. \\
\hline 15 & $\mathrm{c} 7=0, \mathrm{z} 5 \uparrow 0.6$ p.u., $\mathrm{y} 3 \downarrow 0.2$ p.u., $\mathrm{y} 9 \uparrow 0.2$ p.u. \\
\hline 16 & $\mathrm{c} 7=0, \mathrm{z} 5 \uparrow 0.6$ p.u., $\mathrm{y} 3 \downarrow 0.2$ p.u., $\mathrm{y} 8 \uparrow 0.1$ p.u., $\mathrm{y} 9 \uparrow 0.1$ p.u. \\
\hline 17 & $\mathrm{c} 7=0, \mathrm{z} 5 \uparrow 0.5$ p.u., y3 $\downarrow 0.3$ p.u., y9 $\uparrow 0.3$ p.u. \\
\hline 18 & c7 $=0, \mathrm{z} 5 \uparrow 0.5$ p.u., y $\ \downarrow 0.3$ p.u., y $8 \uparrow 0.1$ p.u., y $9 \uparrow 0.2$ p.u. \\
\hline 19 & $\mathrm{c} 7=0, \mathrm{z} 5 \uparrow 0.5$ p.u., $\mathrm{y} 3 \downarrow 0.3$ p.u., $\mathrm{y} 8 \uparrow 0.2$ p.u., $\mathrm{y} 9 \uparrow 0.1$ p.u. \\
\hline 20 & $\mathrm{c} 7=0, \mathrm{z} 5 \uparrow 0.4$ p.u., $\mathrm{y} 3 \downarrow 0.4$ p.u., $\mathrm{y} 8 \uparrow 0.2$ p.u., $\mathrm{y} 9 \uparrow 0.2$ p.u. \\
\hline 21 & c7 $=0, \mathrm{z} 5 \uparrow 0.4$ p.u., $\mathrm{y} 3 \downarrow 0.4$ p.u., $\mathrm{y} 8 \uparrow 0.1$ p.u., $\mathrm{y} 9 \uparrow 0.3$ p.u. \\
\hline 22 & c7 $=0, \mathrm{z} 5 \uparrow 0.3$ p.u., y3 $\downarrow 0.5$ p.u., y $11 \uparrow 0.5$ p.u. \\
\hline 23 & $\mathrm{c} 7=0, \mathrm{z} 5 \uparrow 0.3$ p.u., $\mathrm{y} 3 \downarrow 0.5$ p.u., $\mathrm{y} 8 \uparrow 0.2$ p.u., $\mathrm{y} 9 \uparrow 0.3$ p.u. \\
\hline 24 & $\mathrm{c} 7=0, \mathrm{z} 5 \uparrow 0.2$ p.u., y3 $\downarrow 0.6$ p.u., y $8 \uparrow 0.1$ p.u., y $11 \uparrow 0.5$ p.u. \\
\hline 25 & $\mathrm{c} 7=0, \mathrm{z} 5 \uparrow 0.2$ p.u., y3 $\downarrow 0.6$ p.u., y9 $\uparrow 0.1$ p.u., y $11 \uparrow 0.5$ p.u. \\
\hline 26 & $\mathrm{c} 7=0, \mathrm{z} 5 \uparrow 0.1$ p.u., $\mathrm{y} 3 \downarrow 0.7$ p.u., $\mathrm{y} 8 \uparrow 0.1$ p.u.,y9 $\uparrow 0.1$ p.u., $\mathrm{y} 11 \uparrow 0.5$ p.u. \\
\hline 27 & c7 $=0, \mathrm{z} 5 \uparrow 0.1$ p.u., y $3 \downarrow 0.7$ p.u., y $8 \uparrow 0.2$ p.u., y $11 \uparrow 0.5$ p.u. \\
\hline 28 & $\mathrm{c} 7=0, \mathrm{z} 5 \uparrow 0.1$ p.u., $\mathrm{y} 3 \downarrow 0.7$ p.u., $\mathrm{y} 9 \uparrow 0.2$ p.u., $\mathrm{y} 11 \uparrow 0.5$ p.u. \\
\hline 29 & c7 $=0, \mathrm{y} 3 \downarrow 0.8$ p.u., y8 $\uparrow 0.1$ p.u., y9 $\uparrow 0.2$ p.u., y $11 \uparrow 0.5$ p.u. \\
\hline 30 & c7 $=0, \mathrm{y} 3 \downarrow 0.8$ p.u., $\mathrm{y} 9 \uparrow 0.3$ p.u., $\mathrm{y} 11 \uparrow 0.5$ p.u. \\
\hline
\end{tabular}

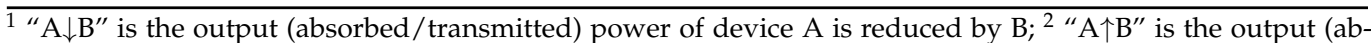
sorbed/transmitted) power of device A is increased by B.

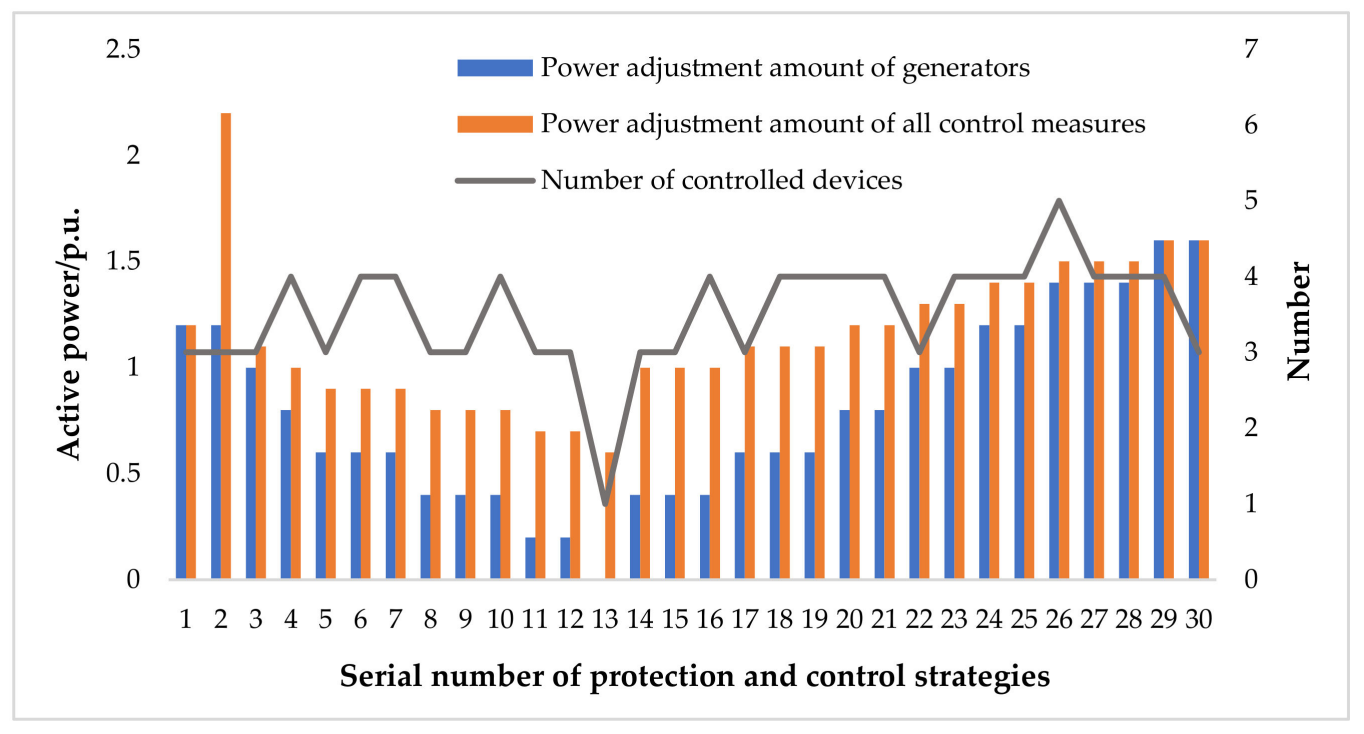

Figure 9. Comparison of protection and control strategies.

\subsubsection{Comparison with Other Methods}

The optimization method proposed in this paper is compared with the method in references $[39,40]$. 
In reference [39], an optimization method with segmented iteration is proposed. The method can only optimize the power adjustment amount of control devices in the continuous interval, and the obtained strategy is: the output power of generator $\mathrm{y} 3$ is reduced by 0.6 p.u., and loads $x 2, x 7, x 6$ and $x 9$ shed loads by 0.13 p.u., 0.06 p.u., 0.13 p.u., and 0.28 p.u., respectively. A load-shedding algorithm to maximize the satisfaction of the power system is proposed in reference [40]. The obtained strategy is as follows: the output power of generator $\mathrm{y} 3$ is reduced by 0.8 p.u., and $\mathrm{x} 1$ sheds loads by $0.8 \mathrm{p} . \mathrm{u}$. Compared with the methods in references $[39,40]$, the method proposed in this study optimizes load-shedding measures and reduces the load loss by $0.6 \mathrm{p} . \mathrm{u}$. and $0.8 \mathrm{p}$.u. The comparison results are shown in Figure 10.

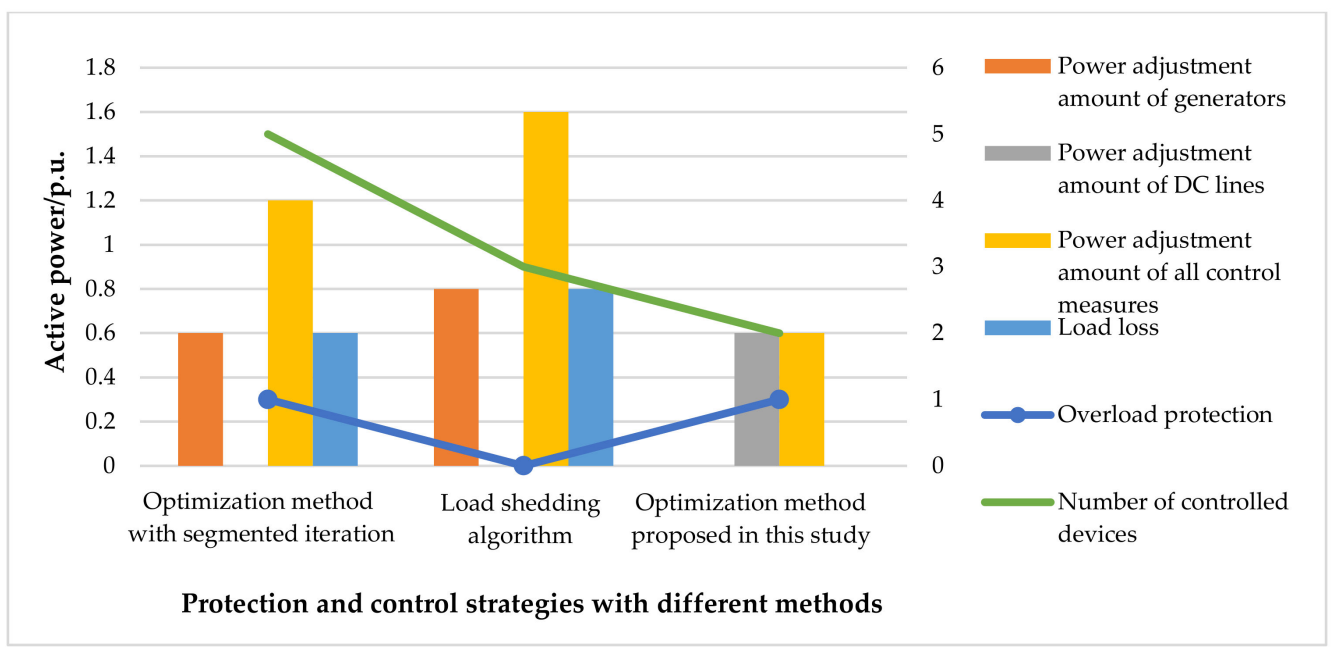

Figure 10. Comparison of different methods.

\section{Conclusions}

Based on PFT and IBSO, the protection and control measures are optimized to mitigate line overloads in the study. The innovations of the proposed method are as follows: (1) The BSO is improved to optimize $0-1$ variables and continuous variables simultaneously; (2) The calculation process is carried out in multiple stages to avoid generating numerous solutions and solve the problem of the solution selection; (3) The generated protection and control strategy can meet the constraints and requirements of practical engineering and effectively reduce the amount of load loss. In this study, the optimization process is focused on active power. However, the active and reactive power are coupled with each other in power systems. For a future study, the interaction between active and reactive power will be explored to realize more efficient coordination and cooperation of protection and control measures.

Author Contributions: All authors contributed to the research in the paper. The work was carried out by N.H. and Z.W., and performed under the advisement from J.H. All authors have read and agreed to the published version of the manuscript.

Funding: This research received no external funding.

Conflicts of Interest: The authors declare no conflict of interest.

\section{References}

1. Upama, N.; Mahshid, R.N.; Md, J.H. Interaction graphs for cascading failure analysis in power grids: A survey. Energies 2020, $13,2219$.

2. Jesus, B.; Jose, M.Y. Integrated risk assessment for robustness evaluation and resilience optimisation of power systems after cascading failures. Energies 2021, 14, 2028.

3. Chao, L.; Jun, Y.; Sun, Y. Risk assessment of power system considering frequency dynamics and cascading process. Energies 2018, 11,422 . 
4. Fan, W.; Liu, Z.; Hu, P. Cascading failure model in power grids using the complex network theory. IET Gener. Transm. Distrib. 2016, 10, 3940-3949.

5. Hou, Y.; Xing, X.; Li, M.; Zeng, A.; Wang, Y. Overload cascading failure on complex networks with heterogeneous load redistribution. Physica A 2017, 481, 160-166. [CrossRef]

6. Lin, X.; Yu, K.; Tong, N. Countermeasures on preventing backup protection mal-operation during load flow transferring. Int. J. Electr. Power Energy Syst. 2016, 79, 27-33. [CrossRef]

7. Liu, Z.; Chen, Z.; Sun, H. Multi-agent system-based wide-area protection and control scheme against cascading events. IEEE Trans. Power Deliv. 2015, 30, 1651-1662. [CrossRef]

8. Fan, J.; Mao, A.; Liu, Y.; Wu, Z.; Wang, C. Analysis of the short-time overload capability of the transmission section based on the load and ambient temperature curve. Power Syst. Prot. Control 2018, 46, 116-121. (In Chinese)

9. Rios, M.A.; Kirschen, D.S.; Jayaweera, D.; Nedic, D.P.; Allan, R.N. Value of security: Modeling time-dependent phenomena and weather conditions. IEEE Trans. Power Syst. 2002, 17, 53. [CrossRef]

10. Li, J.; Zhang, A.; Zhang, H.; Liu, X.; Geng, Y. Study of coordination mechanism between protection and control of regional power grid. In Proceedings of the 34th Chinese Control Conference (CCC), Hangzhou, China, 28-30 July 2015; pp. 8986-8989.

11. Jiang, Y.; Chen, X.; Peng, S. Study on emergency load shedding of hybrid AC/DC receiving-end power grid with stochastic, static characteristics-dependent load model. Energies 2019, 12, 3912. [CrossRef]

12. Majidi, M.; Aghamohammadi, M.R.; Manbachi, M. New design of intelligent load shedding algorithm based on critical line overloads to reduce network cascading failure risks. Turk. J. Electr. Eng. Comput. Sci. 2014, 22, 1395-1409. [CrossRef]

13. Hu, J.; Cao, J.; Yong, T. Multi-level dispatch control architecture for power systems with demand-side resources. IET Gener. Transm. Distrib. 2015, 9, 2799-2810. [CrossRef]

14. Ren, J.; Li, B.; Zhao, M.; Shi, H.; You, H.; Chen, J. Optimization for Data-Driven Preventive Control Using Model Interpretation and Augmented Dataset. Energies 2021, 14, 3430. [CrossRef]

15. Laghari, J.A.; Mokhlis, H.; Bakar, A.H.A. Application of computational intelligence techniques for load shedding in power systems: A review. Energ. Convers. Manag. 2013, 75, 130-140. [CrossRef]

16. Jordehi, A.R. Brainstorm optimisation algorithm (BSOA): An efficient algorithm for finding optimal location and setting of FACTS devices in electric power systems. Electr. Power Energy Syst. 2015, 69, 48-57. [CrossRef]

17. Khazaei, J.; Idowu, P.; Asrari, A.; Shafaye, A.B.; Piyasinghe, L. Review of HVDC control in weak AC grids. Electr. Power Syst. Res. 2018, 162, 194-206. [CrossRef]

18. Ye, P.; Yang, B.; Huang, X. Research on power flow control transformation of HVDC system through PSASP. In Proceedings of the IEEE International Conference on Energy and Environment Technology, Guilin, China, 16-18 October 2009; pp. $232-235$.

19. Zhu, Y.; Guo, Q.; Li, C.; Chang, D.; Chen, D.; Zhu, Y. Research on Power Modulation Strategy for MMC-HVDC and LCC-HVDC in Parallel HVDC System. In Proceedings of the IEEE 3rd Conference on Energy Internet and Energy System Integration (EI2), Changsha, China, 8-10 November 2019; pp. 1456-1461.

20. Wang, J.; Liang, Z.; Xuan, X. Study on power control function for double-circuit-on-the-same-tower HVDC transmission systems. In Proceedings of the IEEE PES Asia-Pacific Power and Energy Engineering Conference (APPEEC), Hong Kong, China, 7-10 December 2014; pp. 1-5.

21. Andrea, B.; Marco, I. Model Predictive Control Application for the Control of a Grid-Connected Synchronous Generator. In Proceedings of the International Electrical Engineering Congress, Krabi, Thailand, 7-9 March 2018; pp. 1-4.

22. Kumars, R.; Seyed, S.H.Y.; Negin, S.M. Power flow control in multi-terminal HVDC grids using a serial-parallel DC power flow controller. IEEE Access 2018, 6, 56934-56944.

23. Chen, B.; Yim, S.; Kim, H.; Kondabathini, A.; Nuqui, R. Cybersecurity of wide area monitoring, protection, and control systems for HVDC applications. IEEE Trans. Power Syst. 2021, 36, 592-602. [CrossRef]

24. Zhang, Q.; Shi, Z.; Wang, Y. Security assessment and coordinated emergency control strategy for power systems with multi-infeed HVDCs. Energies 2020, 13, 3174. [CrossRef]

25. Chandra, C.N.; Banerji, A.; Biswas, S.K. Survey on major blackouts analysis and prevention methodologies. In Proceedings of the Michael Faraday IET International Summit, Kolkata, India, 12-13 September 2015; pp. 297-302.

26. Qi, J.; Dobson, I.; Mei, S. Towards estimating the statistics of simulated cascades of outages with branching processes. IEEE Trans. Power Syst. 2013, 28, 3410-3419. [CrossRef]

27. Zhou, Z.; Wang, X.; Du, D.; Li, Y.; Li, M. A Coordination strategy between relay protection and stability control under overload conditions. Proc. CSEE 2013, 28, 146-153. (In Chinese)

28. Wang, J.W.; Rong, L.L. Robustness of the Western United States power grid under edge attack strategies due to cascading failures. Safety Sci. 2011, 49, 807-812. [CrossRef]

29. Bakhtyar, H.; Hadi, A.M.; Claus, L.B. Centralized load shedding based on thermal limit of transmission lines against cascading events. In Proceedings of the IEEE Power \& Energy Society General Meeting, Chicago, IL, USA, 16-20 July 2017 ; pp. 1-5.

30. Sun, M.; Min, Y.; Chen, L.; Hou, K.; Xia, D.; Mao, H. Optimal auxiliary frequency control of wind turbine generators and coordination with synchronous generators. CSEE J. Power Energy Syst. 2021, 7, 78-85.

31. Islam, R.S.; Sutanto, D.; Muttaqi, K.M. A Distributed multi-agent based emergency control approach following catastrophic disturbances in interconnected power systems. IEEE Trans. Power Syst. 2016, 31, 2764-2775. [CrossRef] 
32. Chen, G.; Wang, Y.; Lu, G.; Hu, J.; You, D.; Zhang, F.; He, Z. An improved load-shedding model based on power flow tracing. In Proceedings of the 12th World Congress on Intelligent Control and Automation (WCICA), Guilin, China, 12-15 June 2016; pp. 1590-1593.

33. Baczyńska, A.; Niewiadomski, W. Power flow tracing for active congestion management in modern power systems. Energies 2020, 13, 4860. [CrossRef]

34. Niu, R.; Zeng, Y.; Cheng, M.; Wang, X. Study on load-shedding model based on improved power flow tracing method in power system risk assessment. In Proceedings of the 4th International Conference on Electric Utility Deregulation and Restructuring and Power Technologies (DRPT), Weihai, China, 6-9 July 2011; pp. 45-50.

35. Subba, R.N.V.; Kesava, R.G.; Sivanagaraju, S. Power flow tracing by graph method using BFS technique. In Proceedings of the International Conference on Advances in Power Conversion and Energy Technologies (APCET), Mylavaram, India, 2-4 August 2012; pp. 1-5.

36. Sobhy, M.A. Transmission loss allocation through complex power flow tracing. IEEE Trans. Power Syst. 2007, 22, $2240-2248$.

37. Shi, Y. Brain storm optimization algorithm. In Proceedings of the 2nd International Conference of Swarm Intelligence, Chongqing, China, 14-16 June 2011; pp. 303-309.

38. Wang, Z. Research on Identification of transmission section and coordination strategy of protection and control measures with multipsource information. Doctoral Dissertation, Beijing Jiaotong University, Beijing, China, 2019.

39. Wang, Z.; Li, J.; Chen, W.; Xiao, Z.; Zhang, X.; Shen, H. Coordination and optimization method of line overload protection and control measures based on subsection iteration. Electr. Power Autom. Equip. 2021, 41, 114-121. (In Chinese)

40. Choi, Y.; Lim, Y.; Kim, H. Optimal load shedding for maximizing satisfaction in an islanded microgrid. Energies 2017, 10, 45. [CrossRef] 